DOI: $10.17805 /$ trudy.2018.5.3

\title{
ГОТОВНОСТЬ ГОСУДАРСТВЕННЫХ СЛУЖАЩИХ К УПРАВЛЕНИЮ ПРОЕКТАМИ
}

\author{
Н. В. Федорова, О. Ю. Минченкова \\ Московский гуманитарный университет
}

Аннотация: В статье выделены критерии оценки готовности государственных служащих к управлению в рамках концепции проектного менеджмента, предложена модель формирования профессиональной готовности государственных служащих к управлению проектами, а также этапы, условия, содержание, формы и методы обучения государственных служащих.

Ключевые слова: государственный служащий; государственная служба; государственное управление проектами; проектная деятельность

\section{READINESS OF GOVERNMENT EMPLOYEES FOR PROJECT MANAGEMENT}

\author{
N. V. Fedorova, O. Yu. Minchenkova \\ Moscow University for the Humanities
}

Аннотация: The article highlighted the criteria for assessing the readiness of government employees for management within the concept of project management. It proposes a model of formation of professional readiness of government employees for project management, as well as the stages, conditions, content, forms, and methods of their training.

Ключевые слова: government employees; public service; public project management; project activities

Проектный подход к управлению в государственной службе в последнее время приобретает все большее значение, что подтверждается наличием различных программ развития России («Социально-экономическое развитие регионов», «Развитие образования», «Управление государственными финансами и регулирование финансовых рынков», «Развитие федеративных отношений и создание условий для эффективного и ответственного управления региональными и муниципальными финансами» и др.), улучшением качества жизни населения, интеграцией в инновационную экономику и переходом в новый технологический уклад.

Сегодня среди системных недостатков государственного управления проектами и программами можно выделить проблемы связанные с несоблюдением государственными заказчиками требований законодательства в сфере разработки и выполнения государственных целевых программ в 
Научные труды Московского гуманитарного университета 2018 № 5

части отсутствия четко определенных задач и мероприятий, предусмотренных в рамках программы, сроков их выполнения, объемов финансирования по годам, результативными показателями реализации программ. Это побуждает к поиску новых подходов к разработке, организации, исполнения и контроля над финансированием государственных целевых программ, которые бы, с одной стороны, обеспечили эффективное управление проектами и программами, а с другой - эффективно координировали действия их исполнителей.

Анализируя научные работы и систематизируя приведенные в них рекомендации по профессионализации государственных служащих в сфере управления социальными проектами, необходимо указать на определенную эпизодичность обращения как отечественных, так и зарубежных исследователей по этой проблематике, в частности по формированию профессиональной готовности государственных служащих к управлению проектами. Однако не подлежит сомнению, что внимание к этому направлению дает новое понимание о возможностях повышения качества профессиональной деятельности государственных служащих.

Под проектом в государственном управлении рассматривается комплексный план мероприятий, предусматривающий вложение информационных, финансовых, интеллектуальных, материальных, трудовых, управленческих и других ресурсов, направленных на достижение качественно нового эффекта, реализуемых в определенный срок.

К специфическим чертам проекта в государственном управлении можно отнести следующие характеристики:

1) расходы несоизмеримы с доходами по объему и форме проявления;

2) период от начала вложений до момента получения эффекта отличается большей продолжительностью по сравнению с вложениями в материальные или финансовые активы;

3) инвестиционные проекты в государственном управлении отличаются высокой чувствительностью к времени (темпоральность);

4) проекты в государственном управлении имеют свойство мультипликации эффектов - в процессе инвестирования происходит интерференция творческих и стабилизирующих вложений, а при получении доходов - «наложение» интернальных и экстернальных эффектов;

5) к реализации проекта привлекаются внешние ресурсы;

6) имеет место взаимодействие мультипроектных или виртуальных команд, реализующих различные мероприятия в рамках одной целевой программы или портфеля проектов.

Можно характеризовать проекты в государственном управлении по следующим признакам: уровню сложности (проект, программа, портфель 
проектов, система); классам (монопроект, мультипроект, мегапроект); продолжительности реализации (краткосрочные, среднесрочные, долгосрочные); сферам деятельности (здравоохранение, наука и образование, культура и спорт, экология, социальная защита и обеспечение, местное самоуправление); направленности (создание эффекта - ценности; инфраструктурные или отраслевые, по предоставлению услуг); источникам финансирования (государственные, региональные, бизнес-структур, целевых фондов, комбинированные); типам управляемой структуры (управляемые извне, управляемые самостоятельно).

В системе государственного управления необходимо соблюдать признанные стандарты и методологию управления проектами, которые применяются на международном уровне, в частности:

1) Project Management Body of Knowledge (PMBoK) — «Свод понятий и практических требований по управлению проектами», разработанный Институтом управления проектами PMI (Project Management Institute);

2) International Competence Baseline (ICB) - «Свод требований к специалистам по управлению проектами», разработанный Международной ассоциацией по управления проектами IPMA (International Project Management Association).

Необходимо также формировать профессиональную готовность государственных служащих к проектному управлению по специально разработанным программам как в системе профессиональной подготовки, так и в системе повышение квалификации.

Анализируя подходы ученых к раскрытию сущности феномена «профессиональная готовность государственных служащих к управлению проектами»» можно констатировать, что профессиональная готовность - это сложная структура, в основу которой положены психофизические состояния, основанные на ценностях конкретной профессии и обеспечивающие личность системой умений и навыков, необходимых для выполнения профессиональных задач (Федорова, Минченкова, 2011: 225).

Структура профессиональной готовности государственных служащих к управлению проектами представлена в табл.

Профессиональную готовность государственных служащих к управлению проектами можно градуировать по уровням. Наличие высокого уровня профессиональной готовности к управлению проектами объединяет государственных служащих, имеющих достаточные знания по разработке и управлению проектами. Они обладают технологией разработки проекта с соблюдением нормативно-правовых требований и анализом эффективности и результативности проекта; осведомлены о структурных элементах и классификации проектов, умеют работать с программным пакетом MS Project. 
Таблица. Структура профессиональной готовности государственных служащих куправлению проектами

\begin{tabular}{|c|c|c|}
\hline Компоненты & Критерии & Показатели \\
\hline \multirow[t]{3}{*}{$\begin{array}{l}\text { Психологи- } \\
\text { ческий }\end{array}$} & $\begin{array}{l}\text { Аксиологически- } \\
\text { мотивационный }\end{array}$ & $\begin{array}{l}\text {-потребность служения на благо РФ и пре- } \\
\text { доставления качественных государствен- } \\
\text { ных услуг в рамках должностной компе- } \\
\text { тенции; } \\
\text {-профессиональная направленность госу- } \\
\text { дарственных служащих на гуманизацию и } \\
\text { демократизацию общественных отноше- } \\
\text { ний; } \\
\text { - морально-ценностные ориентации госу- } \\
\text { дарственных служащих в условиях совре- } \\
\text { менных общественных изменений; } \\
\text {-мотивация государственных служащих } \\
\text { на эффективную реализацию программ и } \\
\text { проектов на различных уровнях государ- } \\
\text { ственного управления }\end{array}$ \\
\hline & личностные & $\begin{array}{l}\text {-толерантность; } \\
\text {-коммуникабельность; } \\
\text {-эмпатия; } \\
\text {-инициативность; } \\
\text {-саморегуляция / самоменеджмент }\end{array}$ \\
\hline & когнитивный & $\begin{array}{l}\text {-знание базовых положений государствен- } \\
\text { ных социальных } \\
\text { проектов, реализуемых в РФ; } \\
\text {-знание нормативно-правовых докумен- } \\
\text { тов, регламентирующих профессиональ- } \\
\text { ной деятельности государственных служа- } \\
\text { щих в процессе управления проектами; } \\
\text {-понимание функций и специфики проект- } \\
\text { ной деятельности и их фундаментальной } \\
\text { роли в развитии социальной инфраструк- } \\
\text { туры государства; } \\
\text {-знание принципов, форм и методов управ- } \\
\text { ления проектами, их классификации и } \\
\text { специфики применения в области государ- } \\
\text { ственного управления; } \\
\text {-знание видов, моделей, организационных } \\
\text { структур проектной команды и специфики } \\
\text { их функционирования при реализации } \\
\text { социальных проектов; } \\
\text {-знание инструментария и процедур раз- } \\
\text { работкипроекта }\end{array}$ \\
\hline
\end{tabular}




\begin{tabular}{|c|c|c|}
\hline \multirow[t]{3}{*}{$\begin{array}{l}\text { Функциональ- } \\
\text { ный }\end{array}$} & $\begin{array}{l}\text { Проектно- } \\
\text { технологический }\end{array}$ & $\begin{array}{l}\text {-умение определять ограничения, страте- } \\
\text { гии и цели проектов; } \\
\text {-способность разрабатывать структурный } \\
\text { план проекта, составлять организацион- } \\
\text { ную схему, определять и описывать роли в } \\
\text { проекте, анализировать окружение проек- } \\
\text { та, составлять календарные планы; } \\
\text {-навыки работы с программой MS Project и } \\
\text { документацией проекта }\end{array}$ \\
\hline & $\begin{array}{l}\text { Экономико-право- } \\
\text { вой }\end{array}$ & $\begin{array}{l}\text {-умение проводить проектный анализ в } \\
\text { соответствии с правовыми норм, действу- } \\
\text { ющих в современном международном и } \\
\text { российском законодательстве; } \\
\text {-умение целесообразно применять раз- } \\
\text { личные методы анализа эффективности } \\
\text { проекта }\end{array}$ \\
\hline & Организационный & $\begin{array}{l}\text {-умение управлять ресурсами, затратами } \\
\text { проектов и пространственно-временной } \\
\text { организацией деятельности проектной } \\
\text { команды; } \\
\text {-умение принимать эффективные решения } \\
\text { с учетом целей проекта }\end{array}$ \\
\hline
\end{tabular}

$\mathrm{У}$ них есть умения и навыки по созданию команды проекта, эффективного управления проектами с учетом основ статусно-ролевого поведения и межличностной совместимости персонала в командной работе; навыки использования методов мотивации и адаптации персонала. Государственный служащий такого уровня является лидером; у него творческий подход к решению задач любой сложности, он генерирует и разрабатывает идеи; знает механизмы управления проектом, а именно основы формирования определенных организационных структур, управления ресурсами и затратами проекта, может быстро принимать эффективные решения с учетом целей проектов и брать на себя ответственность за их выполнение и результат. Он умеет управлять пространственно-временной организацией деятельности проектной команды; активно участвует в интерактивных занятиях, не останавливается на достигнутом, правильно определяет эффективность и результативность проекта. Все это определяет высокий уровень квалификации госслужащего.

Достаточный уровень характеризуется наличием у государственных служащих базовых знаний по разработке и реализации проектов. Государственные служащие знакомы с основами управленческой деятельности, знают механизмы управления проектами, но имеют определенные трудности с применением имеющихся знаний на практике, хотя четко решают поставленные задачи, следуют правилам и определенным технологиям. 
Научные труды Московского гуманитарного университета 2018 № 5

Они имеют понимание о команде проекта, ее функциях, организационной структуры проекта, могут дать четкие определения понятий по управлению проектами. Владеют различными методами анализа, но не всегда могут использовать их правильно, им присуще логико-математическое мышление, что помогает им в управлении ресурсами и затратами. Они достаточно конструктивно взаимодействуют с другими коллегами, конструктивно общаются с подчиненными и руководством.

На низком уровне квалификации находятся государственные служащие, имеющие определенный объем знаний по проектной и управленческой деятельности. Они легко решают задачи, не требующие творческого мышления, много времени и значительных усилий. Участвуют в дискуссиях, но не предлагают свои пути решения. Их умение разрабатывать и внедрять проекты соответствуют тем умением, которые приобретены в течение жизни и не носит характер научности, официальности, деловитости. Навыки работы с MS Project почти отсутствуют, имеются определенные организаторские способности, могут сформировать команду, но не умеют управлять ею. Игнорируют некоторые правила, стараются больше опираться на собственный опыт.

Неудовлетворительный уровень готовности государственных служащих к управлению проектами характеризуется тем, что знания государственных служащих не соответствуют требованиям реализации и управления проектами. Навыки работы с MS Project в них отсутствуют. Они имеют проблемы с организацией и управлением коммуникациями не только в контексте проектной деятельности, но и в профессиональной деятельности вообще. Не могут оперировать математическими данными, что негативно влияет на управления ресурсами и затратами по проекту. Отрицают правила и действуют по своему усмотрению.

Результаты диагностики государственных служащих необходимо положить в основу планирования стратегии развития готовности государственных служащих к управлению проектами.

В основу стратегии формирования готовности государственных служащих по управлению проектами должны быть положены принципы ее формирования. Основным принципом формирования профессиональной готовности государственных служащих к управлению проектами является принцип модульности, который учитывается при определении структуры и содержания учебного плана, предусматривающего целостность и системность, поскольку этот принцип является основным исходным положением какой-либо научной системы, теории, идеологического направления.

Принцип инновационности и интегративности является логическим продолжением принципа модульности, поскольку каждый компонент си- 
стемы существует только во взаимосвязи с другими компонентами с учетом постоянных изменений в структуре, содержании, форм и методов обучения, изменяющихся образовательных потребностей государственных служащих, а также введения в содержание обучения новых дисциплин, спецкурсов, учебных модулей, лекций, тренингов и др.

Принцип гностичности при формировании профессиональной готовности государственных служащих к управлению проектами связан с постоянным обобщением и систематизацией научных знаний, их анализом и синтезом, преобразованием научных знаний в профессиональные, изучением общих закономерностей проектного подхода.

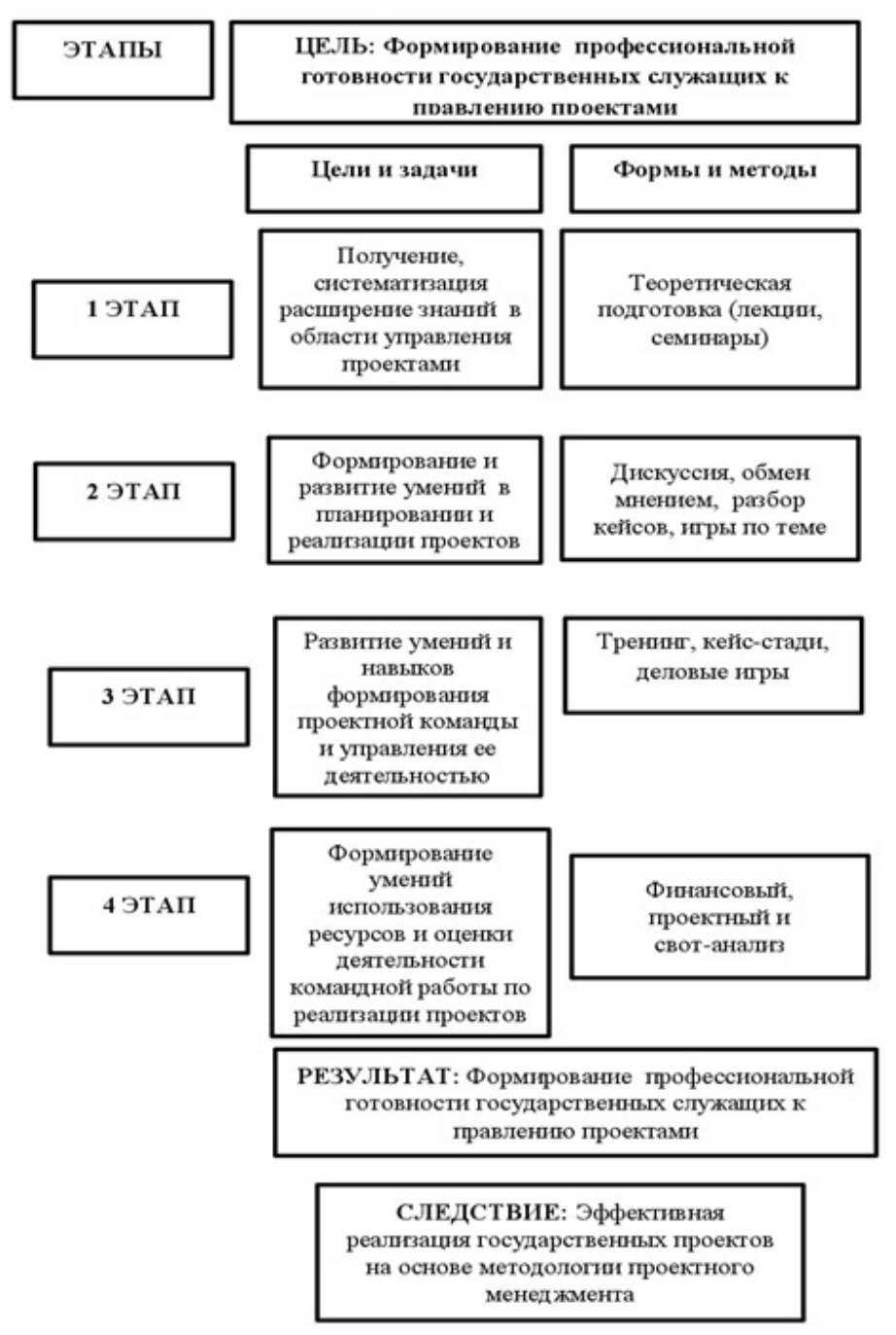

Рис. Модель формирования профессиональной готовности государственных служащих к управлению проектами.

Принцип самоконтроля и самокоррекции связан с созданием общего ритма и режима профессиональной деятельности государственных служа- 
щих в процессе управления проектами, в частности способностью адекватно ставить задачи взаимодействия и уметь выделять проблемную ситуацию.

Принцип реинжиниринга предусматривает перепроектирование деловых процессов для достижения радикального, скачкообразного улучшения деятельности государственной системы.

На основании вышеизложенного можно разработать модель формирования профессиональной готовности государственных служащих к управлению проектами, которая реализуются в четыре этапа (информационно-когнитивный, репродуктивный, деятельностно-креативный и контрольно-аналитический), в их рамках необходимо определить условия, содержание, формы и методы обучения государственных служащих (Федорова, Минченкова, 2016: 43). Такая модель формирования профессиональной готовности государственных служащих к управлению проектами представлена на рис.

Реализация модели формирования профессиональной готовности государственных служащих к управлению проектами позволит повысить эффективная управления государственными проектами на основе методологии проектного менеджмента.

\section{СПИСОК ЛИТЕРАТУРЫ}

Федорова, Н. В., Минченкова, О. Ю. (2011) Управление персоналом : учебник. М. : Кнорусс. 536 с.

Федорова, Н. В., Минченкова, О. Ю. (2016) Экономика труда : учебник для бакалавриата. М. : Кнорусс. 325 с.

Дата поступления: 15.09.2018 2.

Федорова Наталья Васильевна - кандидат экономических наук, доцент, профессор кафедры менеджмента Московского гуманитарного университета. Адрес: 111395, Россия, г. Москва, ул. Юности, д. 5. Тел.: +7 (499) 374-70-13. Эл. адрес: kafedra612@mail.ru

Минченкова Ольга Юрьевна - доктор экономических наук, профессор кафедры менеджмента Московского гуманитарного университета. Адрес: 111395, Россия, г. Москва, ул. Юности, д. 5. Тел.: + 7 (499) 374-70-13. Эл. адрес: olumin@mail.ru

Fedorova Natalya Vasilyevna, Candidate of Economics, Associate Professor, Professor, Department of Management, Moscow University for the Humanities. Postal address: 5, Yunosti St., Moscow, Russian Federation, 111395. Tel.: +7 (499) 374-70-13. E-mail: kafedra612@mail.ru 
Minchenkova Olga Yuryevna, Doctor of Economics, Professor, Department of Management, Moscow University for the Humanities. Postal address: 5, Yunosti St., Moscow, Russian Federation, 111395. Tel.: +7 (499) 374-70-13. E-mail: olumin@mail.ru

\section{Для цитирования:}

Федорова Н. В., Минченкова О. Ю. Готовность государственных служащих к управлению проектами [Электронный ресурс] // Научные труды Московского гуманитарного университета. 2018. № 5. URL: http://journals. mosgu.ru/trudy/article/view/832(дата обращения: дд.мм.гг.). DOI: 10.17805/ trudy.2018.5.3 